\title{
Adsorption Properties and Electrochemical Behavior of Thymus Willdenowii Boiss and Reut Essential Oil as a Green Inhibitor for Mild Steel Corrosion in $1 \mathrm{M} \mathrm{HCl}$
}

\author{
M. Ouknin ${ }^{1}$, P. Ponthiaux ${ }^{2}$, J. Costa $^{3}$ and L. Majidi ${ }^{1, *}$ \\ ${ }^{1}$ Laboratory of Natural Substances and Synthesis and Molecular Dynamics, Faculty of \\ Sciences and Techniques, Moulay Ismail University, 52000 Errachidia, Morocco \\ ${ }^{2}$ Centrale Supélec, Grande Voie des Vignes, Châtenay-Malabry, France \\ ${ }^{3}$ Laboratory of Chemistry of Natural Products, University of Corsica, \\ CNRS UMR 6134 - BP 52,20250 Corte, France \\ "Corresponding author: 1.majidi@fste.umi.ac.ma
}

Received 12/05/2019; accepted 10/05/2021

https://doi.org/10.4152/pea.2022400101

\begin{abstract}
The inhibition effect of Thymus willdenowii Boiss \& Reut essential oil (TW) on the mild steel corrosion in $1 \mathrm{M} \mathrm{HCl}$ has been investigated using weight loss measurements, surface analysis (SEM-EDX, three-dimensional profilometry and FT-IR), potentiodynamic polarization and electrochemical impedance spectroscopy (EIS). The TW oil anticorrosion effect was evaluated using polarization potentiodynamic curves obtained after 30,60 and $90 \mathrm{~min}$ of immersion in a $1 \mathrm{M} \mathrm{HCl}$ medium. Gravimetric results have shown that TW oil has a significant inhibition efficiency value of $81.42 \%$, which was attained at $3 \mathrm{~g} / \mathrm{L}$. The polarization measurements have shown that TW is a mixed type inhibitor, with a significant reduction in cathodic and anodic current densities. Measurements by electrochemical impedance spectroscopy revealed that resistance to the charge transfer has increased with higher TW oil concentrations. From the use of SEM-EDX and three-dimensional profilometry, it is clear that the metal surface has remarkably improved in the TW oil presence, compared to the one exposed to the acid medium without essential oil. From the TW proprieties and the obtained results, it can be concluded that this oil is a new natural substance that can be used against material corrosion in aggressive solutions.
\end{abstract}

Keywords: Thymus willdenowii Boiss \& Reut, corrosion inhibition, SEM-EDX, FT-IR and three-dimensional profilometry.

\section{Introduction}

Hydrochloric acid solutions are used in industrial processes during metals and alloys pickling and cleaning, causing significant metal loss [1,2]. The metal damage by a chemical attack or reaction with its environment is known as corrosion. Recently, research has concentrated on the use of ecologically acceptable compounds, such as essential oils or plant extracts [3]. Essential oils are used as corrosion inhibitors, due to their functional groups that form complexes with metal ions. On the metal surface, these complexes occupy a large specific surface area, thus covering and protecting it from corrosive agents 
present in the solution. The vast majority of metals and alloys used in different human activities are sensitive to different corrosion mechanisms, due to their exposure to different aggressive environments. For this purpose, mild steel (MS) is very important. One of the methods used to reduce the metals corrosion rate is the inhibitors addition. Numerous studies have been conducted to find compounds that can be used as corrosion inhibitors of this metal in different aqueous environments [4].

The Thymus genus belongs to the Lamiaceae family, comprising about 215 species native to the Mediterranean basin. This family, in particular the Thymus genus, is rich not only in essential oils, but also in phenolic compounds, tannins, flavonoids, glycolysed iridoids, quinones, coumarins, terpenoids, saponins and in some cases, pyridines and pyrrolidine alkaloids, which gives it economic and therapeutic importance [5]. Their antioxidant and antimicrobial properties are the key to many applications in processed foods conservation, alternative medicine, pharmaceuticals and natural therapies [6]. In the same way, Thymus essential oils are classified among the most powerful antimicrobial active plants, due to their high activity, particularly against pathogenic antibiotic-resistant microorganisms $[7,8]$. This potent antimicrobial activity is attributed to phenolic components, such as thymol and carvacrol [9, 10]. Indeed, Thymus oils are generally characterized by a high content of thymol and of its carvacrol isomer [11], accompanied by a range of other more or less biologically active compounds, including eugenol, p-cymene, $\alpha$-terpinene and linalool [12].

Thymus willdenowii Boiss and Reut essential oil (TW) is perennial, fragrant, with inflorescences in false whorls, a tubular calyx bell with 10 ribs and with $10-30 \mathrm{~cm}$ in height. The small grey-green leaves are opposite, oblong-lanceolate to linear, 6-10 $\mathrm{mm}$ long and 1-2.5 $\mathrm{mm}$ wide, and gland-dotted. Their margins are recurved. The flowers are light violet, two-lipped [13]. The TW essential oil chemical composition is rich in oxygenated monoterpenes that are mostly represented by a high level of camphor (24.99\%) [14]. It is reported that the Thymus genus has many biological activities, such as antibacterial $[15,16]$, antifungal [16-18], insecticide [19, 20] and antioxidant activities [21].

In the present study, the TW essential oil inhibitive effect on mild steel corrosion in $1 \mathrm{M} \mathrm{HCl}$ was investigated. For this purpose, the study of corrosion parameters was performed by weight loss, electrochemical polarization measurements and electrochemical impedance spectroscopy. The metal surface morphology and the coatings composition were characterized by scanning electron microscopy, energy dispersive spectroscopy (SEM-EDX) and three-dimensional profilometry.

\section{Experimental section}

Essential oil

The studied essential oil was collected from Khenifra (Morocco), and analyzed as described in our previous study [22].

\section{Materials preparation}

The samples used in this survey were cylindrical discs cut from a MS rod with the following composition: 0.1 wt.\% (P), 0.38 wt.\% (Si), 0.02 wt.\% (Al), 0.05 wt.\% (Mn), 0.25 wt.\% (C), 0.07 wt.\% (S) and the remainder iron (Fe), and they 
were used to measure weight loss. The disc was fixed with silicone on a plastic tube as a support, leaving the surface exposed to the corrosive electrolyte. The MS surface was prepared with emery papers, by increasing the grains size (800, 1200 and 2000 grains), rinsed with double-distilled water, degreased with acetone in an ultrasonic bath for $5 \mathrm{~min}$, washed again with double-distilled water and then dried with warm air before use. The $1 \mathrm{M} \mathrm{HCl}$ aggressive solutions were prepared by diluting $37 \%$ grade analytical $\mathrm{HCl}$ with double-distilled water. The TW concentration range was from 0.5 to $3 \mathrm{~g} / \mathrm{L}$. This concentration range has been chosen according to the maximum TW solubility.

\section{Weight loss measurements}

Weight loss measurements were performed in total immersion under stagnant aeration conditions, using $250 \mathrm{~mL}$ beakers with $100 \mathrm{~mL} \mathrm{HCl}(1 \mathrm{M})$, with and without different TW concentrations ranging from 0.5 to $3 \mathrm{~g} / \mathrm{L}$, at a temperature of $298 \mathrm{~K}$. After $6 \mathrm{~h}$ of immersion, MS was carefully washed in double-distilled water, dried and weighed. The rinsing removed the detached segments of the film from the corroded samples. Triplicate experiments were performed in each case, and the mean value of weight loss was reported using an analytical balance (accuracy $\pm 0.0001 \mathrm{mg}$ ). The weight loss enabled us to calculate the average corrosion rate. The corrosion rate $\left(\mathrm{W}_{\text {corr }}\right)$ and inhibition efficiency, $\mathrm{E}_{\mathrm{w}}(\%)$, were calculated as stated in equations (1) and (2), respectively:

$$
\begin{gathered}
W=\frac{\Delta m}{s t} \\
E_{\mathrm{w}}=\frac{W_{\operatorname{corr}}-W_{\operatorname{corr}(i n h)}}{W_{\operatorname{corr}}} \times 100
\end{gathered}
$$

where $\Delta_{\mathrm{m}}(\mathrm{mg})$ is the sample weight before and after immersion in the tested solution, $\mathrm{W}_{\text {corr }}$ and $\mathrm{W}_{\text {corr(inh) }}$ are the weight losses values due to MS corrosion $\left(\mathrm{mg} / \mathrm{cm}^{2} . \mathrm{h}\right)$ in uninhibited and inhibited solutions, respectively, $\mathrm{s}$ is the MS sample $\left(\mathrm{cm}^{2}\right)$ surface and $\mathrm{t}$ represents the exposure time $(\mathrm{h})$. The coverage surface degree was calculated using:

$$
\theta=\frac{\mathrm{W}_{\text {corr } 0}-\mathrm{W}_{\text {corr(inh) }}}{\mathrm{W}_{\text {corr }}}
$$

where $\theta$ represents the surface coverage, and $\mathrm{W}_{\text {corr(inh) }}$ and $\mathrm{W}_{\text {corro }}$ represent the steel corrosion rate in the inhibitor absence and presence, respectively.

\section{Electrochemical studies}

The electrochemical measurements were carried out in a single-compartment electrochemical cell designed for mounting different types of flat samples, for electrochemical tests, with a three-electrode system. The working electrode (WE), in the form of a $2.8 \mathrm{~cm}$ diameter disc, was embedded in polytetrafluoroethylene (PTFE). A saturated calomel electrode (SCE) and a platinum disc electrode were used as reference and auxiliary electrodes, respectively. The temperature was thermostatically controlled at $298 \mathrm{~K}$.

\section{Potentiodynamic polarization curves}

Polarization curve studies were worked out using the EG\&G Instruments potentiostat-galvanostat (model 273A), at $298 \mathrm{~K}$, with and without TW oil 
$(0.5-3 \mathrm{~g} / \mathrm{L})$ in $1 \mathrm{M} \mathrm{HCl}$, at a scanning rate of $0.5 \mathrm{mV} / \mathrm{s}$. Before recording the cathodic polarization curves, the MS electrode was polarized at $-800 \mathrm{Mv}$, for $10 \mathrm{~min}$. For anodic curves, the electrode potential was scanned from its corrosion potential, after $30 \mathrm{~min}$, to the free corrosion potential, at more positive values. The test solution was degassed with pure nitrogen. The experiments allowed the formation of gas bubbles to be maintained. The open circuit potential (OCP) was allowed to a stable state that was obtained after 1800s before electrochemical measurements were performed in the inhibitor (TW) absence and presence.

In the case of the polarization method, the relationship determines the inhibition efficiency $\left(\mathrm{E}_{\mathrm{W}} \%\right)$ :

$$
\mathrm{Ew}_{\mathrm{W}} \%=\frac{\mathrm{I}_{\text {corr }}-\mathrm{I}_{\text {corr(inh) }}}{\mathrm{I}_{\text {corr }}} \times 100
$$

where $\mathrm{I}_{\text {corr }}$ and $\mathrm{I}_{\text {corr(inh) }}$ represent the corrosion current densities in the TW absence and presence, respectively.

\section{Electrochemical impedance spectroscopy (EIS)}

OCP electrochemical measurements and EIS recording over time were worked out using an 273A EG\&G potentiostat model controlled by CorrWarre software. The circular MS exposure surface $(2.8 \mathrm{~cm}$ diameter) to the solution was used as a working electrode. After the steady state current at a given potential was determined, the peak to peak sine wave voltage $(10 \mathrm{mV})$, at frequencies between $10^{-2}$ and $10000 \mathrm{~Hz}$, was superimposed on the remaining potential. The computer programs checked the measurements made at rest potentials after 30, 60 and 90 min of exposure.

Impedance diagrams provided the Nyquist representation. $R_{t}$ and $C_{d l}$ values were obtained from Nyquist plots. The charge-transfer resistance $\left(\mathrm{R}_{\mathrm{t}}\right)$ was measured from the impedance difference at low and high frequencies, as suggested by Tsuru et al. [23] The inhibition efficiency obtained from the charge transfer resistance was calculated according to the following equation (5):

$$
\mathrm{E}_{\mathrm{Rr}} \%=\frac{\mathbf{R}_{\mathrm{r}}^{\prime}-\mathbf{R}_{\mathrm{r}}}{\mathbf{R}_{\mathrm{r}}^{\prime}} \times 100
$$

where $R_{t}$ and $R^{\prime}{ }_{t}$ represent the charge-transfer resistance values without and with inhibitor, respectively.

The double layer capacitance $\left(\mathrm{C}_{\mathrm{dl}}\right)$ and the frequency at which the imaginary component of the impedance is maximal $\left(-Z_{\max }\right)$ are determined by equation (6):

$$
C_{d l}=\frac{1}{\omega \cdot R_{z}} \text { where } \omega=2 \pi \cdot f_{\max }
$$

Impedance diagrams were obtained for the frequency range from 10000- to $10^{-2} \mathrm{~Hz}$, at the OCP for MS in $1 \mathrm{M} \mathrm{HCl}$, in the inhibitor presence and absence.

\section{Surface characterization}

Scanning electron microscopy and energy dispersive X-rays (SEM-EDX)

The samples were immersed in $1 \mathrm{M} \mathrm{HCl}$, in the absence and presence of TW oil optimum concentration, for $6 \mathrm{~h}$ immersion. Then, they were removed, cleaned with double distilled water, dried and finally analyzed by SEM and EDX 
methods. The SEM study was carried out using a FEI Quanta 200, EDAX Metek New XL30 instrument, at an accelerating voltage of $20 \mathrm{kV}$.

\section{Three-dimensional profilometry}

Micrographs of the MS surface, before and after immersion in $1 \mathrm{M} \mathrm{HCl}$ with and without TW oil, were worked out by the micro-topographic method (3D). The surface characterization was performed by the high-resolution optical method, and controlled by the "Surface Map" profilometry software. This method is based on the use of an XY table, which moves over the surface to characterized it under a light pencil which sends a beam of white light onto the surface and analyses the beam reflected from it, by means of a confocal microscopy device equipped with a chromatic lens, allowing distances to be coded by the slow wavelength of the reflected light.

The analysis of the obtained micro-topographic was carried out using the "Mountain Map Universal" software, which allows a wide variety of data processing.

\section{FT-IR analysis}

The chemical composition of MS surfaces in $1 \mathrm{M} \mathrm{HCl}$ in the TW oil presence was studied by FT-IR (Perkin Elmer, UATR Two) analysis. Infrared spectra were recorded using the wave number range from 4000 to $400 \mathrm{~cm}^{-1}$.

\section{Results and discussion \\ Essential oil composition}

To continuous our research on TW activities, we were interested in evaluating the anticorrosion activity of its essential oil. From our previous study, we found that the main compounds of the studied oil are thymol $(43.4 \%), \gamma$-terpinene $(16.3 \%)$ and p-cymene (13.1\%). Besides those, other constituents were detected in low concentrations, including linalol $(3.8 \%)$, borneol $(3.7 \%)$ and carvacrol $(3.2 \%)$ [22].

\section{Weight loss measurement}

The effect of different TW concentrations on the MS corrosion in $1 \mathrm{M} \mathrm{HCl}$ was assessed by weight loss measurements, after $6 \mathrm{~h}$ of immersion. The obtained inhibition efficiency $\mathrm{EW}_{\mathrm{W}}(\%)$ and corrosion rate $(\mathrm{W})$ are represented in Table 1.

Table 1. Mild steel corrosion parameters in $1 \mathrm{M} \mathrm{HCl}$, in the $\mathrm{TW}$ oil absence and presence, obtained from weight loss measurements, at $298 \mathrm{~K}$.

\begin{tabular}{cccc}
\hline $\begin{array}{c}\text { Concentration } \\
(\mathbf{g} / \mathbf{L})\end{array}$ & $\begin{array}{c}\mathbf{W} \\
\left(\mathbf{m g} / \mathbf{c m}^{\mathbf{2}} \mathbf{. h}\right)\end{array}$ & $\begin{array}{c}\text { Ew } \\
\mathbf{( \% )}\end{array}$ & $\boldsymbol{\Theta}$ \\
\hline 0 & 14.69 & - & - \\
0.5 & 7.567 & 48.48 & 0.4848 \\
1 & 6.34 & 56.84 & 0.5684 \\
2 & 4.93 & 66.43 & 0.6643 \\
3 & 2.73 & 81.42 & 0.8142 \\
\hline
\end{tabular}

Table 1 regroups the steel weight loss results in $1 \mathrm{M} \mathrm{HCl}$, in the absence and presence of different TW oil concentrations. It is very clear that the TW oil inhibited the $\mathrm{MS}$ corrosion in a $1 \mathrm{M} \mathrm{HCl}$ solution, at all concentrations used in this study, and that the corrosion rate (W) decreased continuously with higher 
additive concentrations, at $298 \mathrm{~K}$. Indeed, Fig. 1 shows that the MS corrosion rate values decreased with higher inhibitor concentrations, while $\mathrm{TW}$ oil $\mathrm{E}_{\mathrm{w}}(\%)$ values increased with higher concentrations, reaching a maximum value of $81.42 \%$, at a concentration of $3 \mathrm{~g} / \mathrm{L}$. This behavior can be attributed to the increase in the covered surface, $\theta\left(\mathrm{E}_{\mathrm{w}} \% / 100\right)$, and to the essential oil phytochemical components adsorption onto the MS surface, resulting in the reaction sites blocking, and MS surface protection from corrosion active ions attack in the acidic medium. Consequently, we can conclude that the TW oil is a good corrosion inhibitor for MS in $1 \mathrm{M} \mathrm{HCl}$.

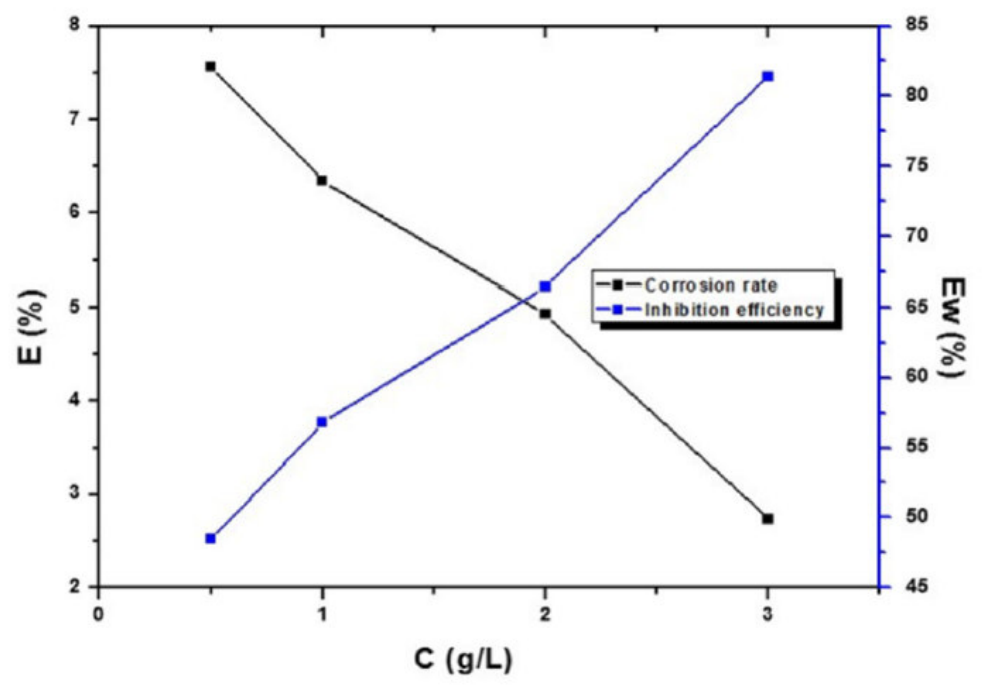

Figure 1. MS corrosion rate $\left(\mathrm{E}_{\mathrm{W}}\right)$ and inhibition efficiency $(\mathrm{E})$ in $1 \mathrm{M} \mathrm{HCl}$ in $\mathrm{TW}$ presence.

\section{Adsorption isotherm and thermodynamic parameters}

It is well known that the inhibitor adsorption process depends on its electronic characteristics, the nature of the metal surface, temperature, steric effects and different degrees of surface activity. In fact, the $\mathrm{H}_{2} \mathrm{O}$ solvent molecules could also be adsorbed at the metal/solution interface. In the aqueous solution, the inhibiting molecules adsorption can be considered as a quasi-substitution process between the aqueous phase inhibitor, $\operatorname{Inh}_{(\mathrm{sol})}$, and the water molecules on the electrodes surface, $\mathrm{H}_{2} \mathrm{O}$ (ads) [24]

$$
\mathrm{Inh}_{(\mathrm{sol})}+\mathrm{xH}_{2} \mathrm{O}_{\mathrm{ads} \leftrightarrow} \mathrm{xH}_{2} \mathrm{O} \text { (sol) }+\mathrm{Inh}_{(\mathrm{ads})}
$$

where $\mathrm{x}$ is the size ratio, that is, the number of water molecules replaced by an organic inhibitor.

To depict the inhibitor adsorption process onto the metal surface, adsorption isotherms were used. The adsorption isotherms from Frumkin, Temkin and Langmuir were used to describe the TW adsorption process onto the metal surface.

The Langmuir adsorption isotherm is associated to the chemisorption or physisorption phenomenon, while the Temkin adsorption isotherm explains the heterogeneity formed on the metal surface. Chemisorption is attributed to Temkin isotherm [25]. In this case, the adsorption isotherms of Langmuir, 
Frumkin and Temkin were applied to explain the TW oil adsorption process onto the MS surface:

$$
\begin{gathered}
\text { Langmuir: } \mathrm{C}_{\mathrm{inh}} / \theta=1 / \mathrm{k}+\mathrm{C}_{\mathrm{inh}} \\
\text { Temkin: } \operatorname{Ln}\left(\mathrm{C}_{\mathrm{inh}} / \theta\right)=\mathrm{LnK}-\mathrm{g} \theta \\
\text { Frumkin: } \operatorname{Ln}\left[\mathrm{C}_{\mathrm{inh}} *(\theta / 1-\theta)\right]=\operatorname{LnK}+\mathrm{g} \theta
\end{gathered}
$$

where $\theta$ is the surface coverage, $\mathrm{K}$ is the adsorption-desorption equilibrium constant, $\mathrm{C}_{\mathrm{inh}}$ is the inhibitor concentration and $\mathrm{g}$ is the adsorbate parameter.

The fraction dependence of the covered surface, $\theta\left(\mathrm{E}_{\mathrm{w}} / 100\right)$, as a function of TW oil concentration $\left(\mathrm{C}_{\mathrm{inh}}\right)$, has been adjusted graphically for these different adsorption isotherms.

The linear regression parameters between $\mathrm{C} / \theta$ and $\mathrm{C}$ are listed in Table 2 , and the $\mathrm{C} / \theta$ straight lines with respect to $\mathrm{C}$ in $1 \mathrm{M} \mathrm{HCl}$, at $298 \mathrm{~K}$, are shown in Fig. 2. It is evident that all linear correlation coefficients $\left(\mathrm{R}^{2}\right)$ are equal to 1 , and that the slope values are also close to 1 , indicating that the TW oil adsorption onto the steel surface obeys the Langmuir isotherm. This result shows that the adsorbed molecules occupied only one site and that there were no interactions with other adsorbed species [26].

Table 2. TW oil adsorption thermodynamic parameters onto mild steel in $1 \mathrm{M} \mathrm{HCl}$, at 298 K, from Langmuir adsorption isotherm.

\begin{tabular}{cccc}
\hline $\begin{array}{c}\text { Temperature } \\
(\mathbf{K})\end{array}$ & $\mathbf{R}^{\mathbf{2}}$ & $\begin{array}{c}\mathbf{K} \\
(\mathbf{l} / \mathbf{g})\end{array}$ & $\begin{array}{c}\Delta \mathbf{G}^{\circ} \\
\left(\mathbf{K J J}^{\circ} \mathbf{m o l}^{-1}\right)\end{array}$ \\
\hline 298 & 0.976 & 1.569 & -18.24 \\
\hline
\end{tabular}

The adsorbed inhibitor tends to desorb from the steel surface. In general, a high $\mathrm{K}$ value is related to a better inhibitory efficiency of a given inhibitor. This is in accordance with the $\mathrm{E}_{\mathrm{w}}$ values obtained from Fig. 2.

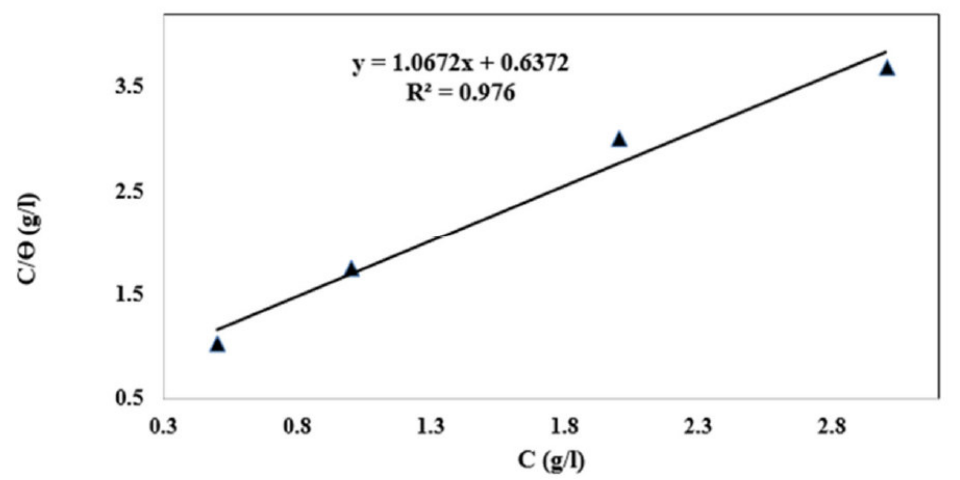

Figure 2. TW Langmuir adsorption isotherm on the MS surface in $1 \mathrm{M} \mathrm{HCl}$, at $298 \mathrm{~K}$.

The thermodynamic parameters are important to better understand the inhibitor adsorption process on the steel/solution interface. The equilibrium adsorption constant, $K$, is related to the standard Gibb's free adsorption energy ( $\Delta \mathrm{G}^{\circ}{ }_{\text {ads }}$ ), with the following equation:

$$
K=(1 / 55.5) \cdot \exp \left(-\Delta \mathrm{G}_{\text {ads }}^{0} / \mathrm{RT}\right)
$$


where $\mathrm{R}$ represents the universal gas constant, $\mathrm{T}$ is the thermodynamic temperature, and the 55.5 value is the water concentration in the solution $\left(10^{3} \mathrm{~g} / \mathrm{L}\right)$.

The high correlation $\left(\mathrm{R}^{2}=0.976\right)$ for part of the Langmuir isothermal inhibitor field confirms the validity of this approach.

The $\Delta \mathrm{G}^{\circ}$ ads negative values suggest that the inhibiting molecules adsorption onto the steel surface was a spontaneous phenomenon (Table 2). It is well known that $\Delta \mathrm{G}^{\circ}$ ads values around $-20 \mathrm{~kJ} \cdot \mathrm{mol}^{-1}$ or less are associated with the physiosorption phenomenon, where electrostatic interaction occurs between the charged molecule and the charged metal, while those around $-40 \mathrm{KJ} \mathrm{mol}^{-1}$ or more are associated with the chemisorption phenomenon, where the sharing or transfer of organic molecules charges at the metal surface take place [3]. In this study, the $\Delta \mathrm{G}^{\circ}$ ads value, calculated and shown in Table 2, supports the TW oil physisorption onto mild steel.

\section{Open circuit potential}

The open circuit potential (OCP) variation with time, for $\mathrm{MS}$ in $1 \mathrm{M} \mathrm{HCl}$, without and with the addition of different TW oil concentrations, is shown in Fig. 3. It can be observed from the figure that stable OCP values were obtained after $1800 \mathrm{~s}$ immersion, both in the inhibitor absence and presence. It is also observed that, after the TW oil introduction into the corrosive medium, the potential shifts to nobler values than those observed in the blank acidic solution. It was found that the positive displacement of the corrosion potential was dependent on the TW concentration. This suggests a possible TW oil influence on both anodic and cathodic polarization.

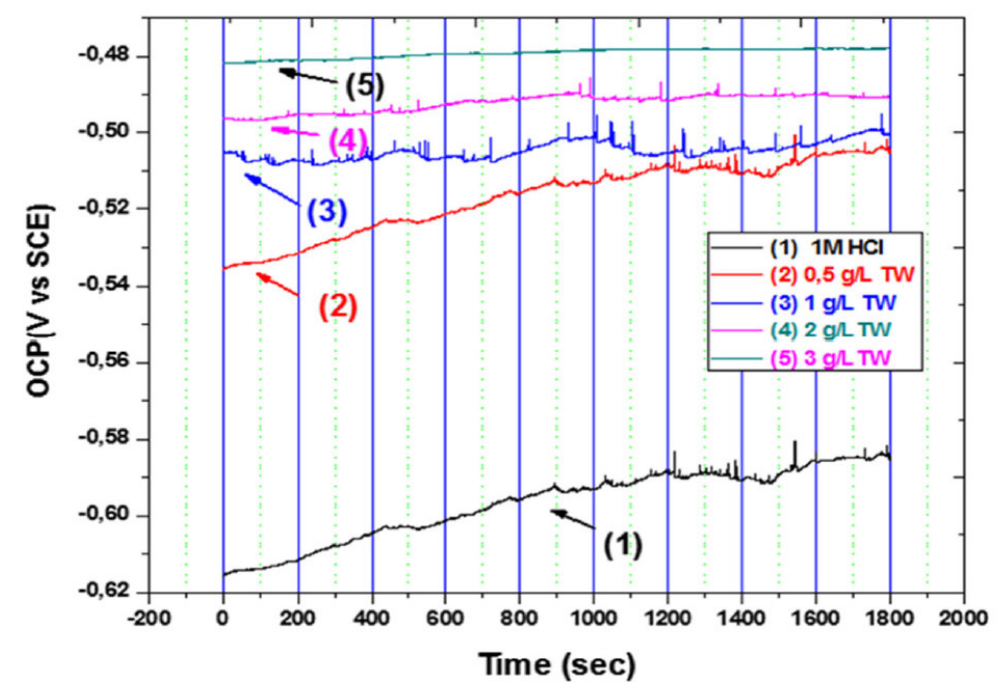

Figure 3. OCP plots for $\mathrm{MS}$ in $1 \mathrm{M} \mathrm{HCl}$, in the $\mathrm{TW}$ absence and in its presence, at different concentrations.

\section{Potentiodynamic polarization curves}

The polarization curves of $\mathrm{MS}$ specimens in $1 \mathrm{M} \mathrm{HCl}$, in the absence and presence of different TW essential oil concentrations, at $298 \mathrm{~K}$, are brought together in Fig. 4. The respective kinetic parameters, including corrosion current density $\left(\mathrm{I}_{\text {corr }}\right)$, corrosion potential $\left(\mathrm{E}_{\mathrm{corr}}\right)$, cathodic slopes $\left(\beta_{\mathrm{c}}\right)$ and inhibition 
efficiency $\left(\mathrm{E}_{\mathrm{W}} \%\right)$, are given in Table 3 . It can be observed from Table 3 that $\mathrm{I}_{\text {corr }}$ decreases considerably with higher inhibitor concentrations. Correspondingly, the inhibition efficiency $\left(\mathrm{E}_{\mathrm{W}} \%\right)$ increases with higher inhibitor concentrations, to reach its maximum value, $83.57 \%$, at $3 \mathrm{~g} / \mathrm{L}$. This behavior suggests that the TW oil adsorptive protective film, formed onto the carbon steel surface, tends to be increasingly complete and stable. The maximum displacement value $\left(\mathrm{E}_{\text {corr }}\right)$ is $69 \mathrm{mV}$, suggesting that the TW oil act as mixed type inhibitor [27].

Table 3. Steel electrochemical parameters, at different TW oil concentrations in $1 \mathrm{M}$ $\mathrm{HCl}$, at $298 \mathrm{~K}$.

\begin{tabular}{cccccc}
\hline $\begin{array}{c}\text { Concentration } \\
(\mathbf{g} / \mathbf{L})\end{array}$ & $\begin{array}{c}\mathbf{E}_{\mathbf{c o r r}} \\
(\mathbf{m V})\end{array}$ & $\begin{array}{c}\mathbf{I}_{\mathbf{c o r r}} \\
\left(\boldsymbol{\mu} \mathbf{A} / \mathbf{c m}^{\mathbf{2}}\right)\end{array}$ & $\begin{array}{c}\boldsymbol{\beta}_{\mathbf{a}} \\
(\mathbf{m V})\end{array}$ & $\begin{array}{c}-\boldsymbol{\beta}_{\mathbf{c}} \\
(\mathbf{m V})\end{array}$ & $\mathbf{I E} \%$ \\
\hline $\mathrm{HCl} \mathrm{1M}$ & 451.80 & 5965.68 & 382.6 & 342.6 & - \\
0.5 & 438.00 & 3658.46 & 358.6 & 284.5 & 38.67 \\
1 & 384.32 & 2151.82 & 226.1 & 226.2 & 63.93 \\
2 & 383.43 & 1091.22 & 165.7 & 151.3 & 81.71 \\
3 & 382.22 & 980.15 & 144.8 & 147.7 & $\mathbf{8 3 . 5 7}$ \\
\hline
\end{tabular}

Fig. 4 represents the MS polarization curves, in the TW oil absence and presence in $1 \mathrm{M} \mathrm{HCl}$, at $298 \mathrm{~K}$. From the polarization curves analysis, it was revealed that the TW oil addition has an inhibitive effect on both anodic and cathodic parts of the polarization curves.

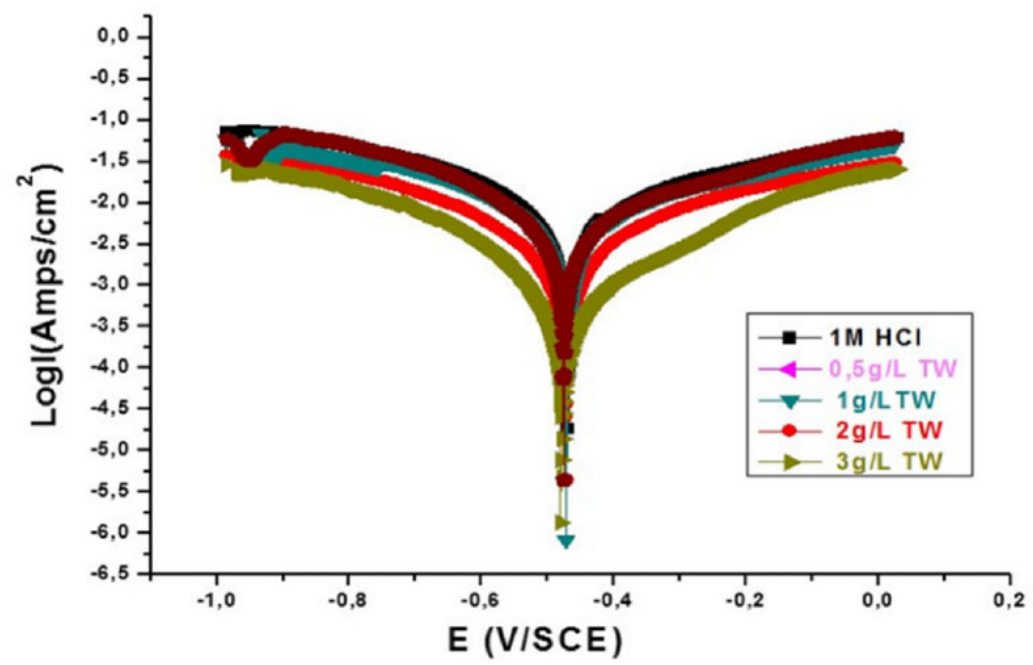

Figure 4. MS anodic and cathodic polarization curves in $1 \mathrm{M} \mathrm{HCl}$, in the $\mathrm{TW}$ absence and in its presence, at different concentrations.

This indicates a change in the cathodic hydrogen evolution mechanism, as well as steel anodic dissolution, suggesting that the inhibitor strongly inhibits the MS corrosion process, and that its capacity as a corrosion inhibitor is improved as its concentration increases. In addition, the cathodic Tafel slope values, $\beta \mathrm{c}$, in the inhibitor presence, change significantly with the TW concentration, indicating its influence on cathodic reactions, and modifying the hydrogen reaction mechanism.

\section{Electrochemical impedance spectroscopy (EIS)}

The MS corrosion behavior in $1 \mathrm{M} \mathrm{HCl}$, in the TW oil presence, was investigated by EIS, at $298 \mathrm{~K}$, after an exposure period of 30, 60 and $90 \mathrm{~min}$. The MS Nyquist 
curves obtained in the TW oil absence and in its presence, at different concentrations, are given in Figs. 5, 6 and 7.

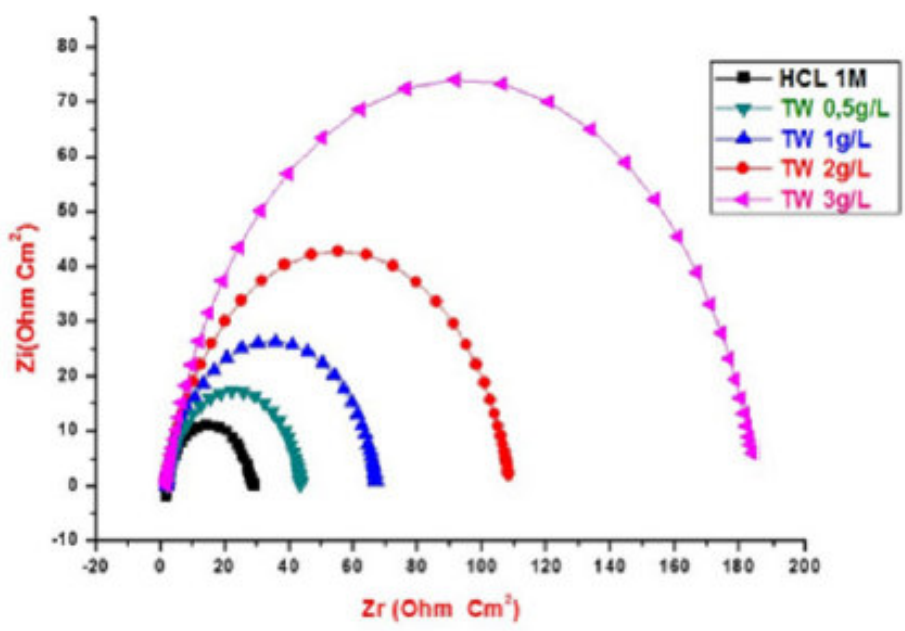

Figure 5. Nyquist diagrams for MS without and with TW, after $30 \mathrm{~min}$ of immersion in $1 \mathrm{M} \mathrm{HCl}$, at various concentrations.

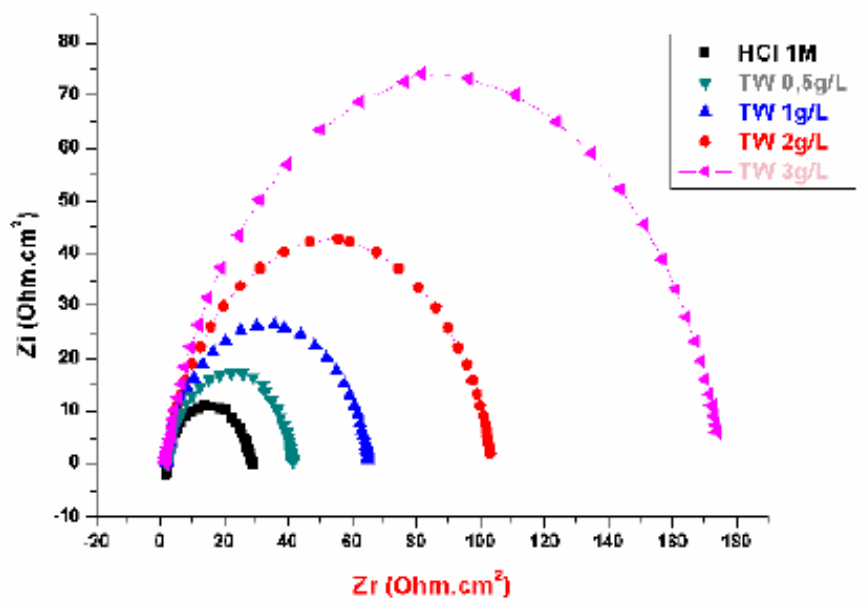

Figure 6. Nyquist diagrams for MS without and with TW, after $60 \mathrm{~min}$ of immersion in $1 \mathrm{M} \mathrm{HCl}$, at various concentrations.

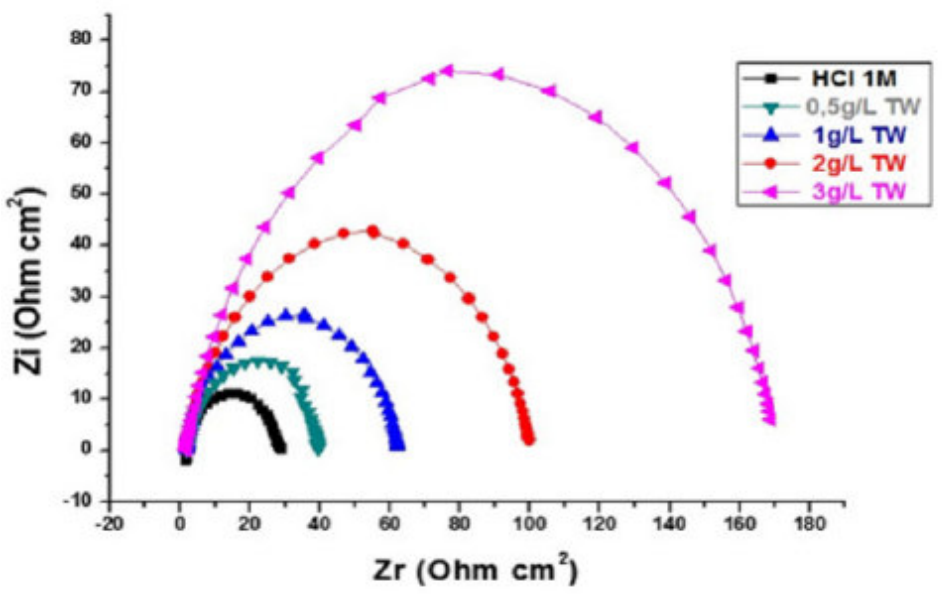

Figure 7. Nyquist diagrams for mild steel without and with $\mathrm{TW}$, after $90 \mathrm{~min}$ of immersion in $1 \mathrm{M} \mathrm{HCl}$, at various concentrations. 
This indicates that the inhibited substrate impedance increases with higher TW oil concentrations, leading to good inhibitive performance. The electrochemical parameters of $\mathrm{R}_{\mathrm{t}}$ (charge transfer resistance), $\mathrm{C}_{\mathrm{dl}}$ (double layer capacity) and $\mathrm{f}_{\max }$ (maximum frequency), derived from the Nyquist diagrams and inhibition efficiency $\mathrm{E}_{\mathrm{W}}(\%)$, are calculated and listed in Table 4 . In accordance with corrosion parameters $\left(R_{t}\right.$, fmax, $C_{d l}$, and $\left.E_{W}\right)$ from Table 4 , it appears that the $R_{t}$ values increase with higher inhibitor concentrations and, consequently, the $\mathrm{E}_{\mathrm{W}}$, at $3 \mathrm{~g} / \mathrm{L}$, is $83.3 \%, 82.25 \%$ and $82 \%$, for 30,60 and $90 \mathrm{~min}$ immersion, respectively.

Table 4. Electrochemical parameters for mild steel after 30, 60 and $90 \mathrm{~min}$ of immersion in $1 \mathrm{M} \mathrm{HCl}$, at various TW oil concentrations.

\begin{tabular}{cccccc}
\hline $\begin{array}{c}\text { Time } \\
(\mathbf{m i n})\end{array}$ & $\begin{array}{c}\text { Concentration } \\
(\mathbf{g} / \mathbf{L})\end{array}$ & $\begin{array}{c}\mathbf{R}_{\mathbf{t}} \\
\left(\mathbf{\Omega . c} \mathbf{c m}^{2}\right)\end{array}$ & $\begin{array}{c}\mathbf{f}_{\max } \\
\mathbf{( H z )}\end{array}$ & $\begin{array}{c}\mathbf{C}_{\mathbf{d l}} \\
\left(\boldsymbol{\mu} \mathbf{F} \mathbf{~ c m}^{\mathbf{2}}\right)\end{array}$ & $\begin{array}{c}\mathbf{E W} \\
\mathbf{\%}\end{array}$ \\
\hline & $\mathrm{HCl} \mathrm{1M}$ & 30.85 & 123.8 & 46.67 & - \\
$\mathbf{3 0}$ & 0.5 & 46.73 & 102.3 & 33.30 & 34.00 \\
& 1 & 70.90 & 81.5 & 27.58 & 56.48 \\
& 2 & 111.20 & 73.3 & 19.55 & 72.22 \\
& 3 & 184.75 & 66.8 & 12.90 & $\mathbf{8 3 . 3 0}$ \\
\hline & HCl 1M & 30.85 & 122.0 & 42.30 & - \\
$\mathbf{6 0}$ & 0.5 & 44.20 & 102.0 & 33.32 & 30.20 \\
& 1 & 68.13 & 82.0 & 28.50 & 54.14 \\
& 2 & 104.19 & 74.0 & 20.65 & 70.40 \\
& 3 & 173.80 & 65.5 & 14.00 & $\mathbf{8 2 . 2 5}$ \\
\hline & HCl 1M & 30.85 & 122 & 42.30 & - \\
$\mathbf{9 0}$ & 0.5 & 42.17 & 102.1 & 37.00 & 26.00 \\
& 1 & 63.20 & 82.0 & 30.72 & 51.18 \\
& 2 & 102.58 & 74.0 & 21.00 & 70.00 \\
& 3 & 171.15 & 67.0 & 13.88 & $\mathbf{8 2 . 0 0}$ \\
\hline
\end{tabular}

Indeed, the TW oil presence is combined with an increase in the $R_{t}$ value in $1 \mathrm{M}$ $\mathrm{HCl}$, confirming a charge transfer process that mainly controls MS corrosion. The double layer capacity values are also reduced to a maximum in the TW oil presence, and the decrease in $\mathrm{C}_{\mathrm{dl}}$ values follows a similar order to that obtained for $\mathrm{I}_{\text {corr. }}$ The decrease in $\mathrm{C}_{\mathrm{dl}}$ is due to the TW oil adsorption onto the metal surface, which results in the formation of a film or complex in the acidic solution. It should be noted that increasing the $R_{t}$ value with higher TW oil concentration increases the corrosion inhibition effectiveness.

\section{Scanning electron microscopy and energy dispersive $X$-rays}

SEM micrographs (Fig. 8, a-b-c) of MS surfaces in $1 \mathrm{M} \mathrm{HCl}$ exhibit the changes which occurred during the corrosion process in the TW oil absence and presence. The MS surface was drastically damaged in $1 \mathrm{M} \mathrm{HCl}$ (Fig. 8, a), but, in the presence of $3 \mathrm{~g} / \mathrm{L}$ of TW oil (Fig. 8, b-c), it was remarkably improved. This indicates the formation of a good protective film by $T$. willdenowii essential oil, which is responsible for corrosion inhibition. The MS EDX spectra contain the peaks corresponding to all elements present in the inhibitor molecules, indicating their adsorption onto the MS surface. The TW oil inhibition effect suggests a high binding of its components on the metal surface, due to the heteroatoms presence, blocking the active sites and, thus, reducing the corrosion rate. In addition, the inhibitive nature of this oil can be attributed to the synergistic 
intermolecular effect of the various active components, such as thymol and carvacrol [31, 32].
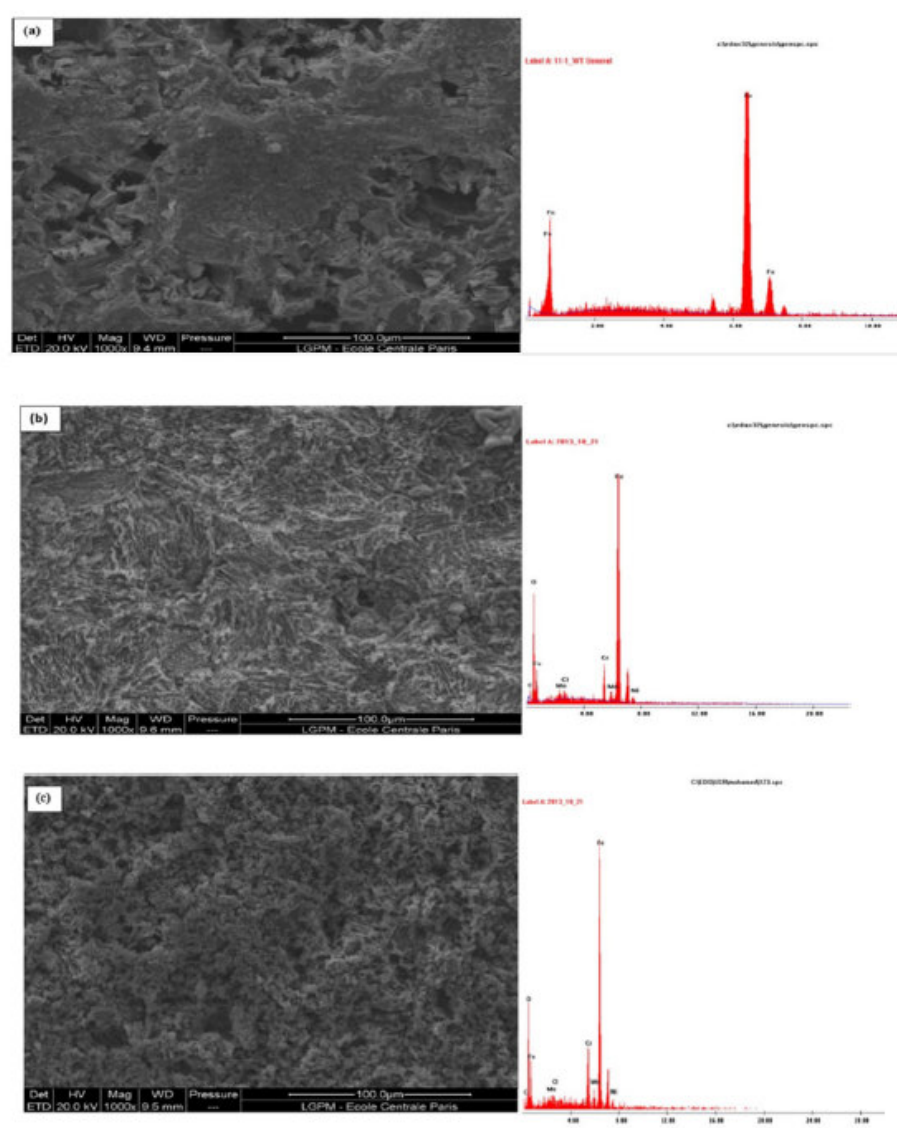

Figure 8. Mild steel SEM-EDX (a) after $6 \mathrm{~h}$ of immersion in $1 \mathrm{M} \mathrm{HCl}$ (b) after $6 \mathrm{~h}$ of immersion in $1 \mathrm{M} \mathrm{HCl}$ with $2 \mathrm{~g} / \mathrm{L}$ of $\mathrm{TW}$ and (c) after $6 \mathrm{~h}$ of immersion in $1 \mathrm{M} \mathrm{HCl}$ with $3 \mathrm{~g} / \mathrm{L}$ TW oil.

\section{Roughness measurements}

The MS surface roughness was evaluated by microtopography (3D), before and after corrosion (Fig. 9), in the TW oil absence, and in its presence, at different concentrations $(0.5-3 \mathrm{~g} / \mathrm{L})$.

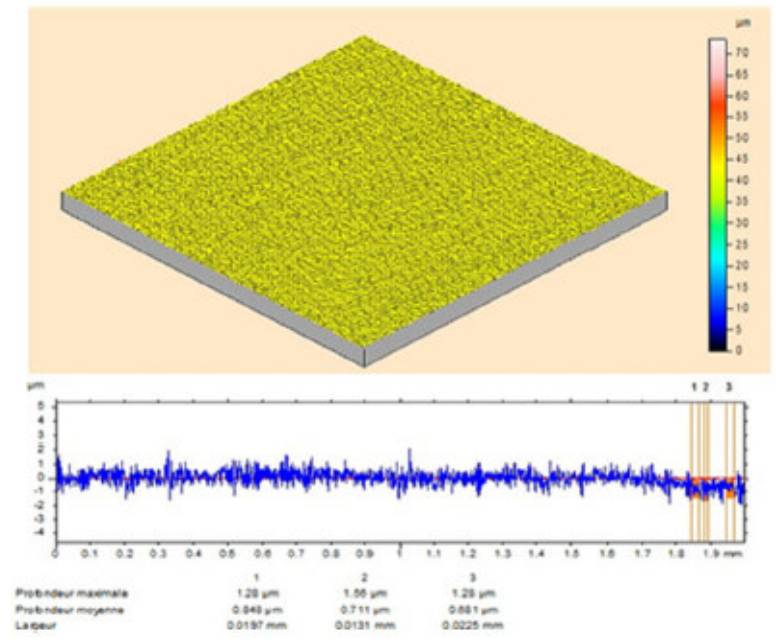

Figure 9. Optical micrographs of MS surface after polishing. 
It is clearly seen from Fig. 10 that the steel sample shows a rough surface, due to acid corrosion.

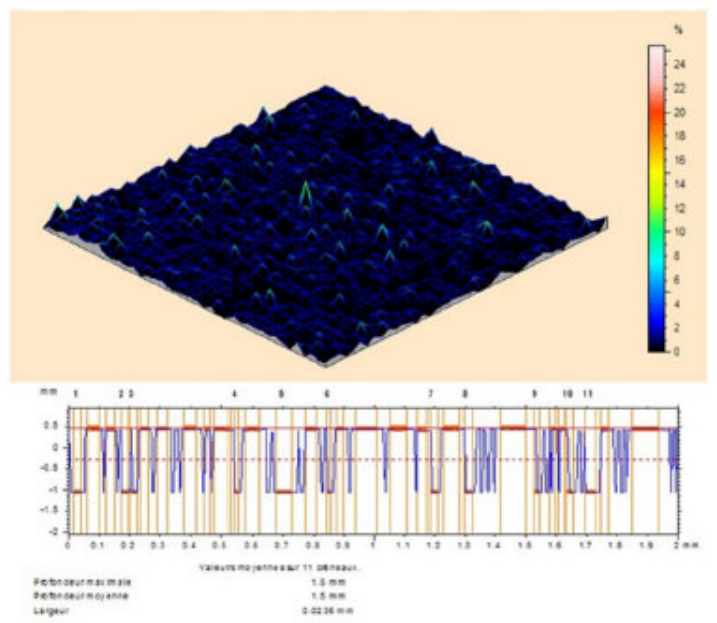

Figure 10. MS optical micrographs after immersion tests in $1 \mathrm{M} \mathrm{HCl}$ without inhibitor.

However, the essential oil $(3 \mathrm{~g} / \mathrm{L})$ presence retarded the corrosion, and the inhibited MS specimen surface got smoothened, as shown in Figs. 11 and 12. The decrease in roughness can be due to the formation of an adsorbed protective film of TW oil components onto the metal steel surface, by the process of physical adsorption.

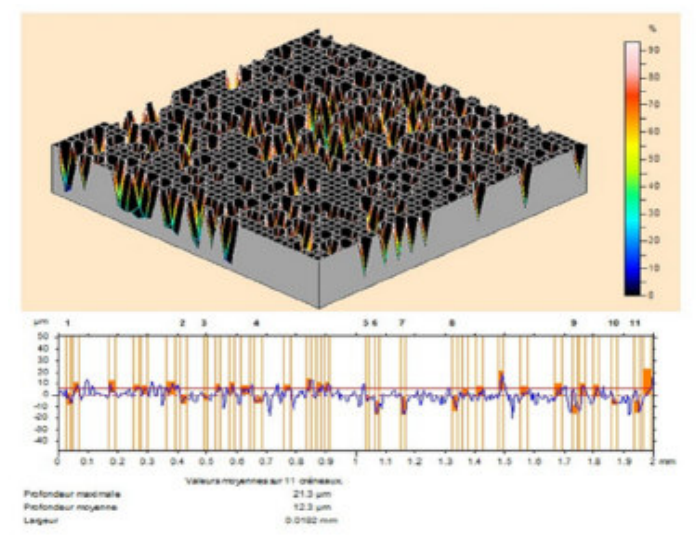

Figure 11. MS optical micrographs after immersion tests in $1 \mathrm{M} \mathrm{HCl}$ with TW presence $(2 \mathrm{~g} / \mathrm{L})$.

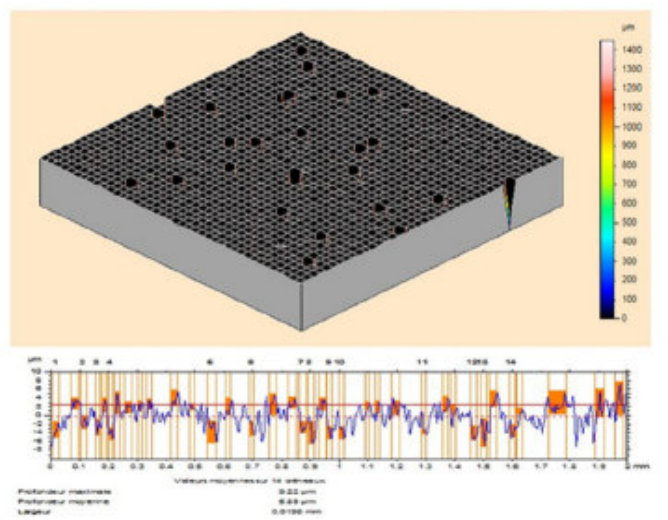

Figure 12. MS optical micrographs after immersion tests in $1 \mathrm{M} \mathrm{HCl}$ with TW presence $(3 \mathrm{~g} / \mathrm{L})$. 


\section{FT-IR analysis}

The important IR absorption inhibitors bands are given in Fig. 13. The strong absorption bands (Fig. 13) are attributed: at $3424 \mathrm{~cm}^{-1}$, to the $\mathrm{O}-\mathrm{H}$ stretching vibration; at $2927 \mathrm{~cm}^{-1}$, to the $\mathrm{C}-\mathrm{H}$ stretching vibration; at $1623 \mathrm{~cm}^{-1}$, to the $\mathrm{C}=\mathrm{O}$ stretching vibration. The $\mathrm{C}-\mathrm{H}$ bending band in $-\mathrm{CH}_{2}$ was found to be at $1407 \mathrm{~cm}^{-1}$. Other absorption bands, at 1138,1102 and $1054 \mathrm{~cm}^{-1}$, are due to the $\mathrm{C}-\mathrm{O}$ stretching vibration.

The absorption bands below $1000 \mathrm{~cm}^{-1}$ correspond to the aliphatic $\mathrm{C}-\mathrm{H}$ group [33]. This result confirms that the TW contains functional groups such as $(\mathrm{O}-\mathrm{H})$ and $(\mathrm{C}=\mathrm{O})$.

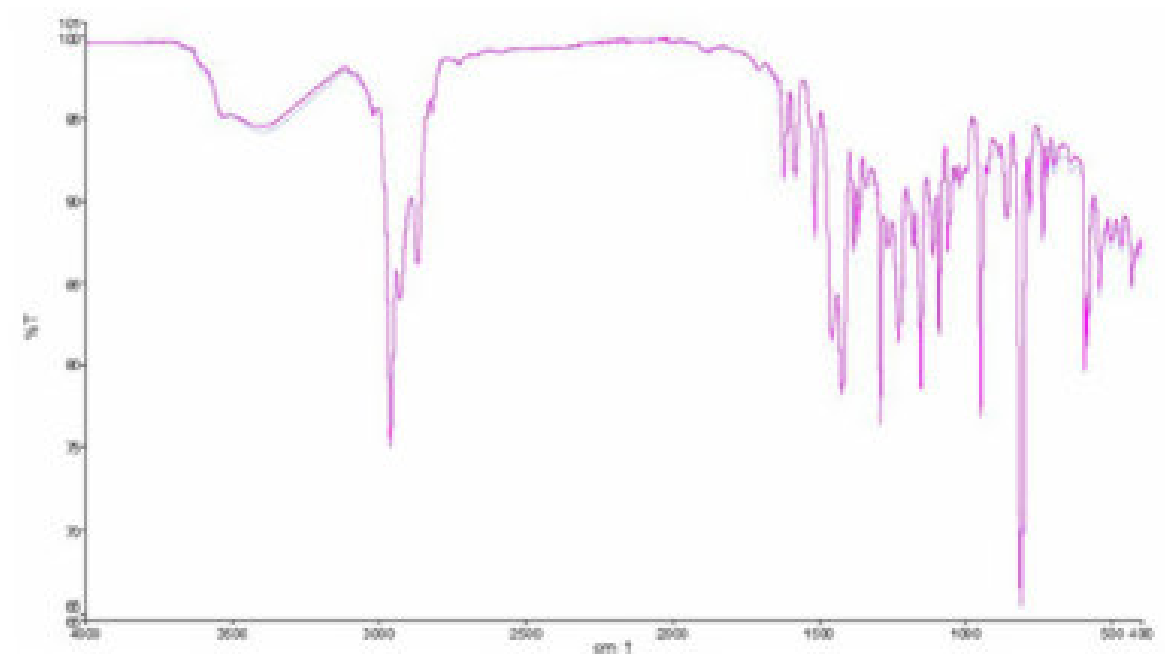

Figure 13. TW film FT-IR spectra on the mild steel surface, after immersion in $1 \mathrm{M}$ $\mathrm{HCl}$ with $3 \mathrm{~g} / \mathrm{L}$ TW oil.

\section{Conclusion}

TW essential oil has been shown to be an effective corrosion inhibitor for mild steel in $1 \mathrm{M} \mathrm{HCl}$, and its inhibition effectiveness is related to concentration and chemical composition. The essential oil, at a concentration of $3 \mathrm{~g} / \mathrm{L}$, showed an inhibition efficiency of $81.42 \%$. The inhibitory action of this oil can be attributed to the phenolic compounds adsorption onto the mild steel surface, such as thymol $(47.3 \%)$ and carvacrol (3.2\%). The results of the potentiodynamic measurements revealed clearly that TW oil is a good mild steel corrosion inhibitor in $1 \mathrm{M} \mathrm{HCl}$.

The TW oil adsorption onto the mild steel surface obeyed the Langmuir adsorption isotherm. The $\Delta \mathrm{G}^{0}$ ads negative sign suggests that the essential oil was adsorbed spontaneously onto the metal surface. The SEM/EDX and microtoporaphic analysis were in accordance with the weight loss and electrochemical results. The higher surface roughness of the mild steel exposed to the blank solution shows a bumpy structure with a large number of ups and downs, due to the acid attack. The mild steel surface morphology in the acidic solution changed with the essential oil addition, due to the formation of an adsorbed protective layer which can be explained by a decrease in the average surface roughness, from $1.5 \mathrm{~mm}$ to $5.89 \mathrm{~nm}$. Finally, microtoporaphic analysis could be used for further studies on the mild steel surface morphology in various environmental conditions. 


\section{Acknowledgments}

This work was partially supported by EU-FP Grant Oil \& Sugar (295202). The authors express their sincere thanks to Prof. Dr. Pierre Ponthiaux and to the technical staff from the Department of Chemical Engineering Laboratory (LGPM, Ecole Centrale Paris, Châtenay-Malabry, France), for the support offered and for giving the permission to do the necessary research work and to use departmental research equipments.

\section{References}

1. Bouyanzer A, Hammouti B, Majidi L, et al. Testing natural fenugreek as an ecofriendly inhibitor for steel corrosion in $1 \mathrm{M} \mathrm{HCl}$. Port Electrochim Acta. 2010;28:165-172. https://doi.org/10.4152/pea.201003165

2. Bahrami MJ, Hosseini SMA, Pilvar P. Experimental and theoretical investigation of organic compounds as inhibitors for mild steel corrosion in sulfuric acid medium. Corros Sci. 2010;52:2793-2803. https://doi.org/10.1016/j.corsci.2010.04.024

3. Khamis E, Bellucci F, Latanision RM, et al. Acid corrosion inhibition of nickel by 2-(triphenosphoranylidene) succinic anhydride. Corros Sci. 1991;47:677-686. https://doi.org/10.5006/1.3585307

4. Yaro AS, Khadom AA, Wael RK. Apricot juice as green corrosion inhibitor of mild steel in phosphoric acid. Alexandria Eng J. 2013;52:129-135. https://doi.org/10.1016/j.aej.2012.11.001

5. Senatore F. Influence of harvesting time on yield and composition of the essential oil of a thyme (Thymus pulegioides L.) growing wild in Campania (Southern Italy). J Agric Food Chem. 1996;44:1327-1332. https://doi.org/10.1021/jf950508z

6. Bozin B, Dukic M, Simin N, et al. Characterization of the volatile composition of essential oils of some Lamiaceae spices and the antimicrobial and antioxidant activities of the entire oils. J Agric Food Chem. 2006;54:1822-1828. https://doi.org/10.1021/jf051922u

7. Burt S. Essential oils: their antibacterial properties and potential applications in foods - A review. Int $J$ Food Microbiol. 2004;94:223-253. https://doi.org/10.1016/j.ijfoodmicro.2004.03.022

8. Hudaib M, Aburjai T. Volatile components of Thymus vulgaris L. from wild-growing and cultivated plants in Jordan. Flavour Frag J. 2007;22:322327. https://doi.org/10.1002/ffj.1800

9. Gutierrez-Larrainzar M, Rua J, Caro I, et al. Evaluation of antimicrobial and antioxidant activities of natural phenolic compounds against foodborne pathogens and spoilage bacteria. Food Control. 2012;26:555-563. https://doi.org/10.1016/j.foodcont.2012.02.025

10. Nostro A, Blanco AR, Cannatelli MA, et al. Susceptibility of methicillinresistant staphylococci to oregano essential oil, carvacrol and thymol. Microbiol Lett. 2004;230:191-195. https://doi.org/10.1016/S03781097(03)00890-5 
11. Bellakhdar J. La pharmacopée marocaine traditionnelle. Médecine arabe ancienne et savoirs populaires. Paris: Rabat, Ibis Press - Eds Le Fennec; 1997.

12. Stahl-Biskup E, Saez F. Thyme: The Genus Thymus. Taylor \& Francis; 2002.

13. Kishore Kumar. Taxonomic and ecological studies on the shola forests of Kerala Thesis. Kerala Forest Research Institute Thrissur, University of Calicut; 2004.

14. Belmalha S, Elidrissi M, Amechrouq A, et al. Chemical characterization of some species of Moroccan middle atlas thyme (region of Midelt). Global J P Applied Chem Res. 2015;2:43-52.

15. Imelouane B, Amhamdi H, Wathelet JP, et al. Chemical composition and antimicrobial activity of essential oil of thyme (Thymus vulgaris) from Eastern Morocco. Int J Agric Biol. 2009;11:205-208.

16. Loziene K, Venskutonis PR, Sipailiene A, et al. Radical scavenging and antibacterial properties of the extracts from different Thymus pulegioides L. chemotypes. Food Chem. 2007;103:546-559. https://doi.org/10.1016/j.foodchem.2006.08.027

17. Pinto E, PinaVaz LC, Salgueiro MJ, et al. Antifungal activity of the essential oil of Thymus pulegioides on Candida, Aspergillus and dermatophyte species. Int J Med Microbiol. 2006;55:1367-1373. https://doi.org/10.1099/jmm.0.46443-0

18. Goncalves MJ, Cruz MT, Cavaleiro C, et al. Chemical, antifungal and cytotoxic evaluation of the essential oil of Thymus zygis subsp. Sylvestris. Ind Crops Prod. 2010;32:70-75. https://doi.org/10.1016/j.indcrop.2010.03.005

19. Lee BH, Annis PC, Choi WS. Fumigant toxicity of essential oils from the Myrtaceae family and 1,8-cineole against 3 major stored-grain insects. J Stored Prod Res. 2004;40:553-564. https://doi.org/10.1016/j.jspr.2003.09.001

20. Saban K, Ahmet C, Hakan O, et al. Antifungal, phytotoxic and insecticidal properties of essential oil isolated from Turkish Origanum acutidens and its three components, carvacrol, thymol and p-cymene. Bioresour Technol. 2008;99:8788-8795. https://doi.org/10.1016/j.biortech.2008.04.048

21. El Ouariachi E, Paolini J, Bouyanzer A, et al. Composition and antioxidant activity of essential oils and solvent extracts of Thymus capitatus from Morocco. J Med Plant Res. 2011;5:5773-5778. https://doi.org/10.5897/JMPR.9000343

22. Ouknin M, Romane A, Costa J, et al. Comparative study of the chemical profiling, antioxidant and antimicrobial activities of essential oils of different parts of Thymus willdenowii. Boiss Reut Nat Prod Res. 2018;33:2398-2401. https://doi.org/10.1080/14786419.2018.1443089

23. Tsuru T, Haruyama S, Gijutsu B. Corrosion Inhibition of Iron by Amphoteric Surfactants in 2M HCl. J Jpn Soc Corros Eng. 1978;27:573-581.

24. Wahyuningrum D, Achmad S, Syah YM, et al. The Correlation between Structure and Corrosion Inhibition Activity of 4,5-Diphenyl-1 vinylimidazole 
Derivative Compounds towards Mild Steel in $1 \% \mathrm{NaCl}$ Solution. Int $\mathbf{J}$ Electrochem Sci. 2008;3:154-166.

25. Cheng S, Chen S, Liu T, et al. Carboxymenthylchitosan as an ecofriendly inhibitor for mild steel in $1 \mathrm{M} \mathrm{HCl}$. Mater Lett. 2007;61:3276-3280. https://doi.org/10.1016/j.matlet.2006.11.102

26. Boumezzourh A, Ouknin M, Bouyanzer A, et al. Ammodaucus Leucotrichus Cosson and Durieu fruits essential oil as corrosion inhibitor of tinplate in $0.5 \mathrm{M}$ oxalic acid medium and its thermodynamic properties. Mor J Chem. 2019;7:141-153.https://doi.org/10.48317/IMIST.PRSM/morjchemv7i1.14387

27. Behpour M, Ghoreishi SM, Mohammadi $\mathrm{N}$, et al. Investigation of some Schiff base compounds containing disulfide bond as $\mathrm{HCl}$ corrosion inhibitors for mild steel. Corros Sci. 2010;52:4046-4057. https://doi.org/10.1016/j.corsci.2010.08.020

28. Bentiss F, Lebrini M, Lagrenée M, et al. Thermodynamic characterization of metal dissolution and inhibitor adsorption processes in mild steel/2, 5-bis (nthienyl)-1, 3, 4-thiadiazoles/hydrochloric acid system. Corros Sci. 2005;47:2915-2931. https://doi.org/10.1016/j.corsci.2005.05.034

29. Szklarczyk M, Velev O, and J. Bockris OM. Atomic Resolution of Carbon and Lead Atoms from Measurements Made in Solution. J Electrochem Soc. $1989 ; 136: 2433-2434$.

30. Benabdellah M, Yahyi A, Dafali A. Corrosion inhibition of steel in molar $\mathrm{HCl}$ by triphenyltin2-thiophene carboxylate. Arabian J Chem. 2011;4:243247. https://doi.org/10.1016/j.arabjc.2010.06.055

31. Bothi RP, Sethuraman MG. Natural products as corrosion inhibitor for metals in corrosive media - a review. Mater Lett. 2008;62:113-116. https://doi.org/10.1016/j.matlet.2007.04.079

32. Ouknin M, Romane A, Costa J, et al. Anticorrosion properties of Thymus munbyanus Boiss and Reut essential oil for mild steel in $1 \mathrm{M} \mathrm{HCl}$. Mor $\mathrm{J}$ Chem. 2018;6:557-568. https://doi.org/10.48317/IMIST.PRSM/morjchemv6i3.11024

33. Lahhit N, Bouyanzer A, Desjobert JM, et al. Fennel (Foeniculum vulgare) essential oil as green corrosion inhibitor of carbon steel in hydrochloric acid solution. Port Electrochim Acta. 2011;29:127-138. https://doi.org/10.4152/pea.201102127 